\title{
Territorialidade e Relações de Poder nos Assentamentos Rurais do Município de Nova Andradina/MS
}

\author{
http://dx.doi.org/10.21527/2237-6453.2020.50.72-88
}

Recebido em: 05/05/2019

Aceito em: 05/08/2019

Fabiano Greter Moreira ${ }^{1}$

\begin{abstract}
RESUMO
O presente estudo tem por objetivo demonstrar como as relações socioespaciais territorializam-se nessa fração de território, apresentando análises da produção camponesa, destacando as diferenças no tamanho dos lotes, o período de criação dos Projetos de Assentamentos (PAs), suas estruturas produtivas, suas relações comerciais, entre outras. Utilizou-se como metodologia a pesquisa qualitativa e a história oral, por meio de entrevistas junto aos assentados do município, preservando sua identidade e de demais participantes da pesquisa. Com os resultados podemos compreender que os processos de configuração territorial nos Projetos de Assentamentos no município de Nova Andradina/MS, possuem várias conflitualidades neste campo de estudo. Estas relações e configurações iniciam-se antes mesmo de se estabelecer um processo de desapropriação, seja com os proprietários de terras e suas relações de poder que envolvem a centralidade agrária à qual estão inseridas, ou mesmo os interesses sociais, políticos e econômicos gerados nos conflitos pelo uso e posse da terra.
\end{abstract}

Palavras-chave: Reforma agrária. Luta pela terra. Questão agrária. Movimento dos trabalhadores rurais sem terra.

\section{TERRITORIALITY AND POWER RELATIONS IN RURAL SETTLEMENTS IN THE MUNICIPALITY OF NOVA ANDRADINA/MS}

\section{ABSTRACT}

The objective of this study is to demonstrate how socio-spatial relationships are territorialized in this fraction of the territory, presenting analyzes of peasant production, highlighting the differences in the size of the lots, the period of creation of the Settlement Projects (PAs), their productive structures, their relationships commercial, among others. Qualitative research and oral history were used as methodology, through interviews with the settlers of the municipality, preserving their identity and of other participants in the research. With the results we can understand that the processes of territorial configuration in the Projects of Settlements in the municipality of Nova Andradina/MS, have several conflicts in this field of study. These relations and configurations begin even before a process of expropriation is established, be it with landowners and their power relations that involve the agrarian centrality to which they are inserted, or even the social, political and economic interests generated in the conflicts by the use and possession of the land.

Keywords: Land reform. Fight for land. Agrarian question. Movement of landless rural workers.

\footnotetext{
${ }^{1}$ Doutor em Geografia pela Universidade Federal da Grande Dourados (UFGD). Professor da Universidade Federal de Mato Grosso do Sul (UFMS).fabiano.gm12@hotmail.com
} 
Os Projetos de Assentamentos (PAs) Rurais são permeados por relações sociais conflituosas constantemente. As diversidades de relações pautadas nos indivíduos dentro e fora dos lotes marcam a face vivida de luta destes atores sociais no campo brasileiro. Nesse pedaço de território várias são as relações de poder manifestadas, como a resistência na luta pela desapropriação de terras, para manter os processos de produção camponesa nas organizações coletivas dentro dos assentamentos, o que, por conseguinte, provoca transformações e rupturas sociais no convívio diário desses atores sociais em seus lotes.

Para compreendermos as faces das relações de poder nessas frações do território nos assentamentos rurais, buscamos em Raffestin (1993, p. 16), na sua obra "Por uma geografia do poder", contextualizar as manifestações sociais que deixam evidente que a "territorialidade se manifesta em todas as escalas espaciais e sociais, que, de certa forma, é a face vivida da face agida do poder" sobre elas. Os ambientes de assentamentos rurais possuem várias relações sociais conflitantes, que são dirigidas por indivíduos que buscam interesses e alianças para fins comuns ou objetivos particulares, sobrepondo-se aos assentados, aos seus líderes e outros interessados na comunidade local.

A territorialidade das relações de poder que transitam nos assentamentos rurais do município de Nova Andradina permite verificar o caráter próprio ou distinto de cada assentado em seus lotes e comunidades pertencentes. O produto dos atores sociais que, para Raffestin, é o território, é também um produto vivenciado pelos indivíduos, mesmo se não participaram da configuração daquele novo meio. As relações produtivas nos lotes e de redução social nos assentamentos, conduzem os assentados a vivências assimétricas em suas propriedades, pois cada um está diante de uma ação de poder em seu lote.

A produção agropecuária territorial nos assentamentos está presente nas relações sociais que potencializam o poder dos indivíduos por meio da formação de sistemas organizativos pelos assentados, ou mesmo os movimentos dirigidos por estes atores sociais no que diz respeito à luta pela posse da terra ou à reivindicação pela reforma agrária no Brasil, movimentos sociais que estabelecem relações de poder desde o período dos acampamentos, seguidos da entrega dos lotes e acompanhamento na luta pela permanência na propriedade. Como todo território é formado por relações de poder, os assentamentos rurais são complexos sistemas de territorialidade da estrutura agrária do país, sejam eles assentados, com sua cultura e dinâmica de vida próprias ou um indivíduo imerso nas relações mercantis, seja pela inserção nos mercados locais por meio de intermediários ou exigências mercadológicas e/ou políticas públicas que induzem à produção capitalista.

Segundo Fernandes (2008, p. 42), o território pode "significar o espaço físico como: o espaço geográfico de uma nação, de uma região ou município, de uma propriedade ou moradia", mas pode significar também os "espaços sociais como: dimensões culturais, políticas e econômicas", ou seja, "territórios em movimento", representados em seu sentido relacional de sua complexidade, espacialidade e temporalidade. Os atores do campo ocupam terra, conquistam o assentamento, migram, trabalham, produzem, vendem, consomem, industrializam, estudam, lutam, reocupam terras, enfim, contribuem com o desenvolvimento local da região inserida. 
Há abordagem territorial nos assentamentos rurais mediante a compreensão e definição do geógrafo Raffestin (1993), que comenta que espaço e território não correspondem ao mesmo valor geográfico, pois o território se forma a partir de um determinado espaço; já o espaço é dado, ou seja, um local de possibilidades em que os indivíduos podem praticar ou manifestar sua intenção de se apoderar dele. Este território produzido no espaço possui um limite, que é manifestado em uma determinada área em que é preciso delimitar as operações de acordo com as relações estabelecidas entre o espaço e os atores envolvidos.

A questão agrária ultrapassa barreiras físicas e econômicas em um assentamento rural. Suas relações sociais permitem "recriar a sua própria existência" conforme Fernandes (2015), seja do indivíduo ou de sua família, sendo esta recriação o modo de contradizer a centralidade agrária do poder dos grandes sobre os pequenos do "moderno" ao "tradicional", do lucro à troca de mercadorias, contribuindo a novos redirecionamentos de vida no campo.

$\mathrm{O}$ artigo tem por objetivo demonstrar como as relações socioespaciais territorializam-se na fração de território dos Projetos de Assentamentos (PAs) do município de Nova Andradina/MS. O trabalho está estruturado com uma introdução, seguida do percurso metodológico utilizado na pesquisa e a descrição da área dos assentamentos rurais do município. Como aporte teórico e de discussão dos resultados, buscou apresentar as perspectivas das relações de poder nos Assentamentos Rurais de Nova Andradina e suas territorialidades construídas pelos assentados. Finaliza com algumas considerações e as referências bibliográficas empregadas no estudo.

\section{METODOLOGIA}

O percurso metodológico adotado para a realização deste trabalho foi a pesquisa qualitativa, a partir da necessidade de conhecer, por intermédio de observação, reflexão e análise, a realidade do fenômeno social, para compreendê-lo nos processos contextuais, segundo Triviños (1987). Estas percepções e a realidade do fenômeno social são pontos fundamentais para contextualizar as relações de poder e de territorialização dos assentados e os assentamentos rurais do município de Nova Andradina/MS. Minayo (2002) descreve o trabalho de campo como um recorte baseado na construção teórica de uma determinada fração de momento, realizada por meio de entrevistas, observações, levantamentos de material documental e bibliográfico, que buscam aspirar as experiências e vivências dos fenômenos nos participantes da pesquisa.

A pesquisa seguiu a operacionalização do "ponto de saturação" para definir a quantidade de entrevistas realizadas, formulado por Daniel Bertaux, ${ }^{2}$ que, para Alberti (2004, p. 37), ocorre quando uma "pesquisa oral começa a se tornar repetitiva, produzindo cada vez menos informação". Mesmo chegando a este ponto, é necessário que o pesquisador o ultrapasse para se certificar da validade das entrevistas.

\footnotetext{
${ }^{2}$ A operacionalização do ponto de saturação, formulado por Daniel Bertaux (BERTAUX, Daniel. Los relatos de vida: perspectiva etnosociológica. Barcelona: Bellaterra, 2005).
} 
A coleta de informações no estudo de campo foi realizada a partir de entrevistas semiestruturadas junto aos participantes preestabelecidos na pesquisa. Optou-se por entrevistas semiestruturadas no trabalho, seguindo, ainda, percursos metodológicos descritos por Poupart et al. (2014, p. 212), que tratam a entrevista como de ordem ética e política, porque abre "possibilidades de compreender e conhecer internamente os dilemas e questões enfrentadas pelos atores sociais", instrumento privilegiado de acesso às experiências dos atores como ferramenta de informação na pesquisa qualitativa, neste caso assentados dos assentamentos rurais do município de Nova Andradina/MS.

Nas últimas três décadas foram efetivados no município de Nova Andradina quatro Projetos de Assentamentos (PAs), de acordo com o Instituto Nacional de Colonização e Reforma Agrária (INCRA, 2018), sendo estabelecidos da seguinte forma:

a) O Projeto de Assentamento Casa Verde localiza-se na Rodovia MS-134 que liga Nova Andradina ao Distrito de Nova Casa Verde, com uma área territorial de 29.859,9889 ha, com capacidade de 471 lotes, e, atualmente, segundo o Incra (2018), possui 460 famílias assentadas.

b) O Projeto de Assentamento Santa Olga localiza-se na Rodovia MS-276, Km 167, que liga Nova Andradina à cidade de Ivinhema, e foi o último assentamento a ser criado no município, possuindo uma área territorial de 1.492,5021 ha com capacidade de 170 lotes segundo o Incra (2018), e possui 168 famílias assentadas.

c) O Projeto de Assentamento Teijin localiza-se na Rodovia MS-134, que liga Nova Andradina ao Distrito de Nova Casa Verde ou à Rodovia BR-267, que liga o Estado do Mato Grosso do Sul ao Estado de São Paulo, com uma área territorial de 28.497,8194 ha, com capacidade de 1.094 lotes segundo o Incra (2018), e possui 1.056 famílias assentadas.

d) O Projeto de Assentamento São João situa-se na antiga Fazenda São João, localizada no município de Nova Andradina, Rodovia BR-267 km $172+100$ m, que liga o Distrito de Nova Casa Verde à Nova Alvorada do Sul, com uma área territorial de 4.011,9000 ha, com capacidade de 180 lotes segundo o Incra (2018), e possui 172 famílias assentadas.

Foram realizadas 19 entrevistas, assim divididas quatro no PA São João, cinco no PA Casa Verde, cinco no PA Teijin e cinco no PA Santa Olga. O recorte temporal da pesquisa foi realizado no período de outubro de 2017 a janeiro de 2018, restringindo as entrevistas apenas aos participantes que atendiam os seguintes critérios: a) primeiro ${ }^{3}$ (a) titular do lote (fator de suma importância, por nos proporcionar maiores informações sobre a trajetória de luta e permanência nos lotes); b) responsável pelo lote (com o objetivo de compreender a dinâmica de luta nos lotes e suas relações sociais no assentamento); c) residir no lote (somente os moradores fixos nos lotes permitirão maiores informações do assentamento e os conflitos socioterritoriais).

\footnotetext{
${ }^{3}$ Ao decidir o primeiro ou primeira titular do lote, buscou-se compreender a trajetória dos assentados desde o período de acampamentos, a espera da desapropriação, as lutas pela posse e permanência nos lotes, e, neste sentido, pesquisar as relações de poder e a construção das territorialidades dos assentamentos do município de Nova Andradina/MS dos primeiros atores sociais dos PAs, apresentando adequadamente as relações conflituosas desde a criação dos assentamentos.
} 
As entrevistas foram gravadas com gravador de áudio e transcritas para posterior aprovação dos participantes, seguindo orientações de Meihy e Ribeiro (2011). Não foram reveladas as identidades dos participante que não concordaram com a sua identificação e a de seu lote. As entrevistas foram realizadas no lote de cada participante e/ ou em local definido pelo próprio assentado, e tiveram duração de aproximadamente 1 hora, dependendo da disponibilidade dos participantes. Para tanto, padronizamos a identificação dos participantes da seguinte maneira: Assentamento Teijin (TJ1, TJ2, TJ3, TJ4, TJ5), Assentamento Casa Verde (CV1, CV2, CV3, CV4, CV5), Assentamento São João (SJ1, SJ2, SJ3, SJ4) e Assentamento Santa Olga (SO1, SO2, SO3, SO4, SO5). Os demais participantes da pesquisa foram identificados com apenas as letras iniciais de seus nomes.

\section{ÁREA DE ESTUDO}

O município de Nova Andradina está localizado no sudeste do Estado de Mato Grosso do Sul, e conta com um número populacional estimado de 53.517 habitantes (IBGE, 2018). O município foi fundado em 20 de dezembro de 1958 e instalado oficialmente no dia 30 de abril do ano seguinte, em 1959, quando se desmembrou da comarca de Rio Brilhante, pertencente, até então, ao município de Bataguassu.

O município ocupa o 8 o lugar em número populacional de acordo com as estimativas do IBGE realizadas no ano de 2018, dos 79 municípios do Estado de Mato Grosso do Sul, tendo como antecessores os municípios de Campo Grande (885.711), Dourados (220.965), Três Lagoas (119.465), Corumbá (110.806), Ponta Porã (91.082), Sidrolândia (56.081) e Naviraí (54.051).

O pecuarista paulista Antônio Joaquim de Moura Andrade (1889-1962) chegou à região de Nova Andradina por volta de 1938, quando adquiriu do Estado a Fazenda Caapora, que passou a chamar-se Fazenda Primavera (hoje pertence ao município de Batayporã) e é o mesmo colonizador de Andradina, localizada no interior de São Paulo. Em 1957 o paulista desmembrou uma gleba da Fazenda Baile (adquirida em 1951). Foi neste período que se deu início aos trabalhos nas terras que hoje compõem Nova Andradina. Após este processo, foram loteadas outras propriedades rurais, oferecendo grandes vantagens aos migrantes. A ação culminou em uma acelerada povoação da região, contando com um relevante número de paulistas, paranaenses, mineiros e, principalmente, nordestinos, que se deslocaram ao então embrião da cidade (PMNA, 2017).

Conhecida como a "Capital do Vale do Ivinhema", Nova Andradina possui localização estratégica na confluência de Mato Grosso do Sul, São Paulo e Paraná, o que contribuiu para a expansão de um modelo de economia, principalmente no tocante à criação e abate de bovinos, o que lhe rendeu o título de "Capital do Boi" pela importância de ser um dos principais polos pecuários do Brasil.

Pela Lei municipal no 241, de 31-10-2000, foi criado o distrito de Nova Casa Verde e anexado ao município de Nova Andradina. Em divisão territorial datada de 2003, estabeleceu o município em dois distritos: Nova Andradina e Nova Casa Verde (PMNA, 2017).

Dentre os municípios citados em níveis populacionais, apresentamos uma relação dos Projetos de Assentamentos Rurais das referidas cidades e suas representações em capacidade de famílias assentadas, número de assentamentos e áreas, de acordo com a Tabela 1. 
A Tabela 1 nos revela que o município de Nova Andradina está em 8 o lugar em número populacional de habitantes, mas, quando se trata de áreas de assentamentos rurais, 0 município fica em 3ㅇ lugar entre os oito mais populosos do Estado, com 23,30\% do total de áreas dos PAs, atrás apenas de Sidrolândia, com 29,20\% e Ponta Porã, com 29,54\%, dos mais de 270 mil hectares de áreas de Assentamentos no Estado de Mato Grosso do Sul.

Tabela 1 - Assentamentos rurais dos municípios

\begin{tabular}{|c|c|c|c|c|c|c|}
\hline Municípios & $\begin{array}{c}\text { № } \\
\text { Assentamentos }\end{array}$ & $\%$ & $\begin{array}{c}\text { Famílias } \\
\text { Assentadas }\end{array}$ & $\%$ & Área PA & $\%$ \\
\hline Campo Grande & 3 & 5,17 & 269 & 2,50 & $4.280,5033$ & 1,56 \\
\hline Dourados & 2 & 3,45 & 212 & 1,96 & $5.197,6612$ & 1,89 \\
\hline Três Lagoas & 3 & 5,17 & 120 & 1,11 & $3.729,7892$ & 1,36 \\
\hline Corumbá & 7 & 12,10 & 1.221 & 11,30 & $33.570,3933$ & 12,25 \\
\hline Ponta Porã & 15 & 25,86 & 3.006 & 27,82 & $80.886,9269$ & 29,54 \\
\hline Sidrolândia & 23 & 39,65 & 4.007 & 37,08 & $80.011,4174$ & 29,20 \\
\hline Naviraí & 1 & 1,70 & 113 & 1,05 & $2.453,1666$ & 0,90 \\
\hline Nova Andradina & 4 & 6,90 & 1.856 & 17,18 & $63.862,2104$ & 23,30 \\
\hline Total & 58 & 100 & 10.804 & 100 & $273.992,0683$ & 100 \\
\hline
\end{tabular}

Fonte: Adaptada a partir do Painel de Assentamentos do Incra (INCRA, 2018).

Apresentamos, a seguir, a Figura 1 com o mapa da localização dos assentamentos rurais do município de Nova Andradina nos âmbitos de Brasil e Estado de Mato Grosso do Sul.

Figura 1 - Mapa da localização dos assentamentos rurais no município de Nova Andradina no âmbito de Brasil e Estado de Mato Grosso do Sul

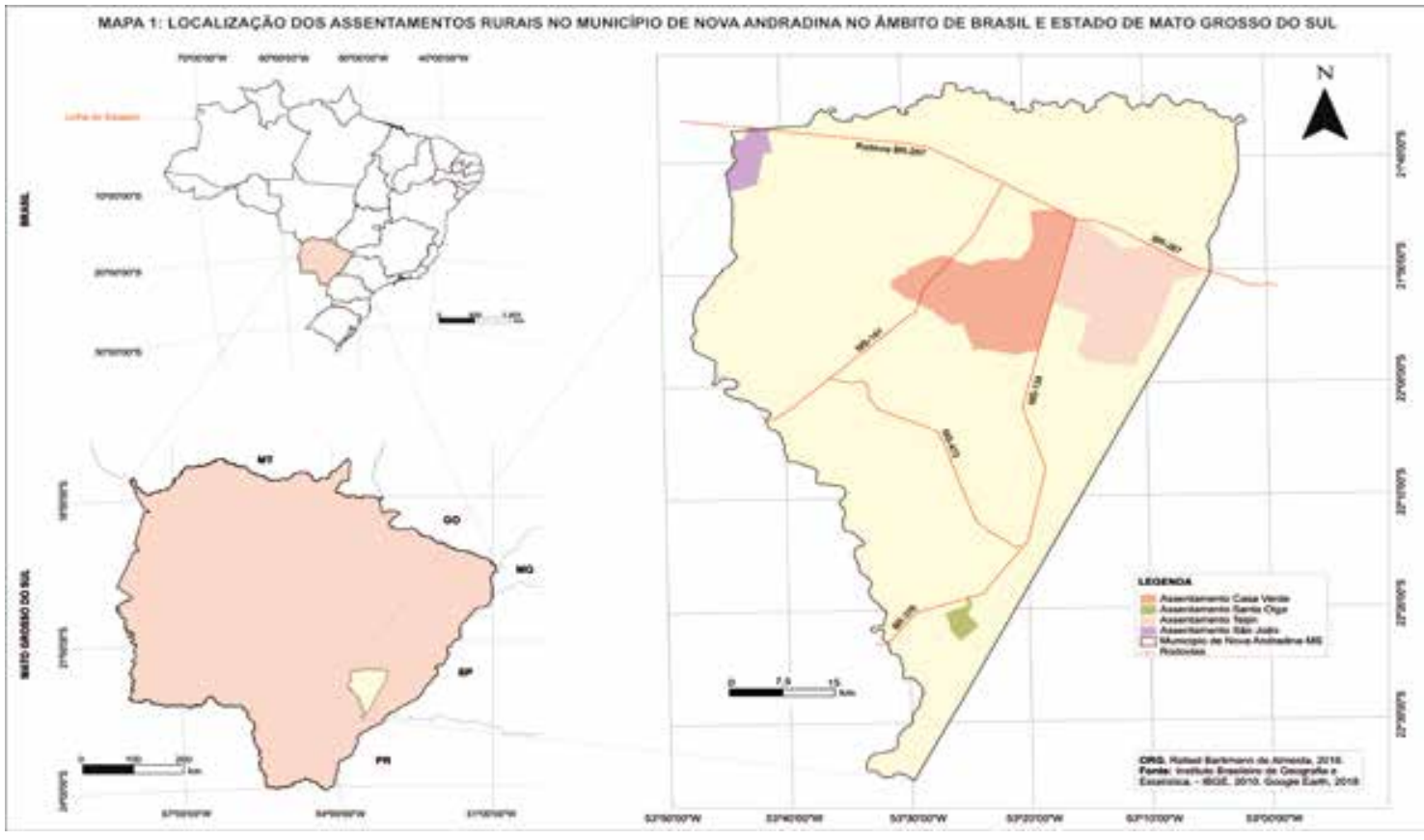

Fonte: Adaptado a partir de dados do IBGE (2018).

Os assentamentos rurais no município de Nova Andradina estão entre os maiores assentamentos em extensão territorial do Estado de Mato Grosso do Sul e do país, segundo dados emitidos pelo Incra (2018). A área total dos assentamentos é de aproxima- 
damente 64 mil hectares, $13,86 \%$ do total do território do município, conforme aponta o Censo Agropecuário de 2006 (IBGE, 2006), com capacidade para assentar 1.915 famílias em seus projetos. O Projeto de Assentamento com maior área territorial é o Casa Verde, com 46,75\% do total da área de PAs do município, com lotes de vários tamanhos, podendo chegar a mais de 100 ha. O menor é o Santa Olga, com 2,33\% de área e em torno de 6 ha cada lote (somadas as áreas societária e individual).

\section{PERSPECTIVAS DAS RELAÇÕES DE PODER NOS ASSENTAMENTOS RURAIS DE NOVA ANDRADINA/MS}

As relações de poder que permeiam os assentamentos rurais estão evidenciadas nos mais diversos eventos dentro desta fração de território. As relações existenciais, descritas por Raffestin (1993), são evidenciadas, desde o período de acampamento, à entrada no lote, sua permanência e produção, e, ainda, nas organizações sociais instaladas dentro dos assentamentos. As cooperativas e associações são ambientes que exercem grande poder no processo organizativo dos assentamentos, pois são estas organizações que permitem acesso a programas de vendas de alimentos, aquisição de insumos e equipamentos agrícolas, unindo as forças dos assentados em um único objetivo: o fortalecimento e a permanência das pessoas no campo.

Com a pesquisa foi possível compreender sobre o cargo de direção das cooperativas sob o olhar dos assentados. O assentado SO2 (entrevista realizada dia 3/10/2017 - Assentamento Santa Olga) nos declara o seguinte entendimento de direção de cooperativa:

Precisa primeiramente nos assentamentos rurais preparar os futuros diretores para que possam estar preparados em dirigir e organizar as cooperativas e associações de assentados. Muitos assentados se iludem com o poder da posição provisória do cargo na entidade, e acham que pode tudo, e não é bem assim. Como em qualquer instituição, seja em cooperativa, sindicato, associação, enfim, desde que você pegou um poder e começa a ficar "arrogante", pode provocar conflitos com a coletividade, "perdendo a força da união dos assentados". O "poder na mão" das pessoas "pode provocar grandes rupturas sociais nas organizações coletivas dentro dos assentamentos rurais" (grifo do autor).

A relação de poder que se estabelece na condição de presidente, diretor, fiscal e/ ou conselheiros e qualquer outro cargo em uma organização social nos assentamentos rurais, é algo transitório, de momento de mandato, sem aval de propriedade. $\mathrm{O}$ "poder na mão" e o "pode tudo", a que se refere o assentado, deve possuir o propósito de fortalecer e criar condições de fortalecimento dos assentados no campo. À medida que esta condição se converte em ações para fins individuais e/ou de grupos ligados aos mesmos, fomenta a discórdia entre os assentados, tornando a luta pelo acesso a terra semelhante ao capitalismo que os instituiu como sem-terra.

Outra condição de posição de poder está centrada nas relações de controle e ordem dos assentamentos, que Fernandes (2015) trata como "os grandes sobre os pequenos". Quando falamos de grandes em relação aos pequenos em nosso país, isso não é novidade, pois o Brasil concentra as maiores riquezas sob o comando de uma parcela pequena da sociedade, enquanto a grande maioria é subordinada a esta classe dominante. $\mathrm{O}$ que, todavia, acontece nos assentamentos é a influência externa a favor 
de proprietários que não foram acampados, que, às vezes, nem assentados são, e apenas possuem lote ou lotes, conforme seu poder de compra para agregar capital. São condições que favorecem àqueles que não lutaram pela posse da terra e aparecem de maneira desigual no que se refere à legalidade dos lotes perante aos seus primeiros acampados. Este evento foi relatado pelo assentado CV1 (Assentamento Casa Verde), que assistiu vários lotes adquiridos por "terceiros", sendo formalizados/legalizados de maneira mais eficaz do que dos próprios assentados.

Dentro do assentamento já formado. Depois que veio os títulos, infelizmente o meu não veio ((risos)), mas "outros conseguiram comprar, legalizar e passar a documentação".

A pessoa que procura vender busca sempre quem tem "influência", com isso, a interferência externa, junto aos órgãos competentes, contribui com as "legalizações" pertinentes à posse da terra (assentado CV1, entrevista realizada dia 9/10/2017 Assentamento Casa Verde - grifos do autor).

Os tratamentos diferenciados que ocorrem nos órgãos públicos não são raros, mas, em se tratando das relações sociais no campo, isso é mais recorrente, sobretudo nos assentamentos rurais. A ausência de assistência técnica rural pelo Incra e as dificuldades provenientes do próprio dia a dia dos assentados, aliadas ao desconhecimento das burocracias institucionais, os tornam ainda mais fragilizados no campo.

Não bastando estas situações procedentes da questão agrária brasileira, os assentados passam a ver privilégios e/ou facilitações estendidos a outros (podem ocorrer com terceiros, ou, até mesmo, com assentados ligados a pessoas influentes na sociedade) que possuem lote(s) nos assentamentos que, na maioria das vezes, são "terceiros", em virtude de influências de políticos ou partidos coligados ou pessoas ditas da sociedade, com objetivos de legalização de lotes, vantagens de informações, compras/vendas de lotes, entre outras negociações.

Em outro momento um depoimento revela tensões entre agentes do Incra e assentado. Teria ocorrido uma condição de quase exclusão do assentado de seu lote, fazendo com que o mesmo fosse obrigado a se deslocar a Campo Grande para se defender de palavras incitantes de abandono do lote e demais acontecimentos relatados por um dos servidores do órgão. Conforme relato do assentado CV2, ele foi surpreendido em um momento tenso e doloroso de sua luta pela posse de seu lote:

Recebi uma notificação (cartinha) do Incra para comparecer na sede da instituição em Campo Grande. Era um momento difícil para mim, pois na época minha mãe estava doente e internada em um hospital de Campo Grande. Quando cheguei à sede do Incra procurei o gerente da instituição na época, e o mesmo me disse: que eu não morava aqui no assentamento, que eu morava fora do assentamento. Eu respondi a ele que estava de brincadeira comigo, e repliquei a ele questionando que ele não passa em meu lote, e o mesmo questionou mais uma vez: "não, eu passo lá e eu não te vejo". Foi uma discussão feia, onde este gerente me acusava não ser o assentado que "morava no meu lote", dizendo que havia outra pessoa lá dentro. Mesmo afirmando que morava no lote, o mesmo me ameaçou dizendo: "Você perdeu o seu lote". Depois deste fato, descobri que o outro lote, vizinho ao meu, "era desse representante do INCRA" (assentado CV2, entrevista realizada dia 17/10/2017 - Assentamento Casa Verde - grifos do autor). 
Este evento nos permite afirmar que as relações de poder que assim circulam nos espaços de assentamentos rurais manifestam dimensões das relações presentes na questão agrária do país. A luta pela posse da terra no Brasil é submetida por manifestações contraditórias e particulares em cada assentamento, porém as problematizações de poder, sustentadas por Foucault (1988), revelam que as relações de poder estão em todos os níveis, em todas as comunidades, evidenciadas desde o grande ao pequeno, do Estado ao povo, do assentado aos assentados. Não podemos nos limitar a pensar que o poder se encontra apenas na classe dominante, mas vários pontos intermediários tentam influenciar e se apropriar desta influência. Quando se busca compreender as relações existenciais de poder, precisamos entender como estas relações se dão e se colidem, pois a fração de território dos assentamentos possui desde assentados, consumidores, eleitores, famílias, estudantes, enfim, uma rede de pessoas que se relaciona em vários meios da sociedade e forma as sociedades locais.

A trajetória de desapropriação, de acampamentos e a entrada na propriedade pelos assentados, percorre vários momentos conflitantes, compilados pelas relações de poder nesta fração de território capitalista. Entre eles estão o Estado, que possui o poder de institucionalização e criação dos projetos de assentamentos, os proprietários de terra, que possuem a centralidade agrária de posse e monopólio da terra, e os movimentos sociais e sindicatos ligados à luta pela terra, que lideram e influenciam os locais e as formas de organização de seus acampamentos. Foram analisadas situações manifestadas nas quais os assentados/acampados estiveram engendrados sobre relações existenciais de poder na criação e na permanência nos projetos de assentamentos do município de Nova Andradina.

No Assentamento Teijin, criado pela desapropriação da Fazenda Teijin, parte das lutas dos assentados pela reforma agrária os levaram a viver por anos em barracos de lona às margens da rodovia MS-134 aguardando pela autorização do Estado. Além da morosidade do Estado, com o Incra responsável pela administração da reforma agrária no país na esfera federal, outro ponto contribuiu de forma ainda mais penosa aos assentados do PA Teijin. Por ser de propriedade de um grande grupo empresarial japonês, várias foram as decisões judiciais favoráveis e desfavoráveis à desapropriação. Com o poder de possuir uma assessoria jurídica, oprimiram os assentados na não desapropriação em todas as instâncias legais possíveis, porém, em última instância realizada no Supremo Tribunal Federal, a ministra Ellen Gracie decidiu como favorável a desapropriação e a retirada total dos animais da propriedade. As seguidas ordens judiciais em momento algum deixaram os assentados intimidados, pois não iriam deixar de resistir nunca pela desapropriação das terras, segundo relato dos participantes da pesquisa. Estas problematizações, que, para Foucault (1988), são chamadas de contrapoder, instituem os mecanismos de resistência que os assentados possuem em sua luta pela posse da terra.

A territorialidade, descrita por Raffestin (1993), que foi manifestada no Assentamento São João, evidencia que o poder do mais forte acomete àqueles que estão à margem de políticas públicas inoperantes em sua escala espacial. Mesmo que ocorra a desapropriação, podem acontecer novas relações existenciais que se manifestam de acordo com os interesses daquela fração de território capitalista. Nesta territorialidade, foi manifestado o domínio de quem já estava naquela propriedade, não o proprietário, mas o mais interessado pela fazenda: o arrendatário. 
Conforme relato dos participantes, na criação do PA São João o poder do arrendatário de terra ultrapassou o diálogo e a esfera judicial, com agressão física e moral, com a força de arma de fogo e com intimidações, com o objetivo de expulsar os assentados que aguardavam o corte de seus lotes. A resistência ocorreu por parte dos assentados, que tiveram momentos de terror vividos pelas famílias, permanecendo sob ameaças de jagunços armados, que chegou a ser manchete nacional. Após a prisão dos jagunços pela polícia militar, aguardaram a divisão dos lotes pelo Incra, retomando o ciclo de relações de poder à espera da efetividade das políticas públicas de reforma agrária do país.

No Assentamento Casa Verde, de acordo com o assentado CV1 (entrevista realizada dia 9/10/2017), a desapropriação da Fazenda Santa Virgínia trouxe benefícios ao proprietário da terra, que, interessado pela venda, procurou o Incra para a negociação. Grande parte da propriedade era cerrado, possuindo apenas uma sede e algumas casas, contudo a propriedade necessitava de investimentos para produção e criação de animais. Os assentados foram conduzidos pela Federação dos Trabalhadores na Agricultura do Estado de Mato Grosso do Sul (Fetagri) para acampar na sede da propriedade e aguardar o sorteio dos lotes. A entrega dos lotes, feita pelo Incra aos assentados acrescidos de incentivos - como toma se vira, o lote é esse aí-, relatado pelos participantes da pesquisa, revela mais uma etapa de resistência dos assentados na construção de sua vida no assentamento, que transcorre, primeiramente, para desbravar, ou, melhor dizendo, desmatar o seu lote, e, em segundo, criar/recriar sua organização de produção camponesa em seus lotes.

Encontramos no Assentamento Santa Olga assentados que também estiveram acampados no Teijin. Eles receberam o convite do Sindicato de Trabalhadores Rurais de Batayporã para comparecer, pois poderia ser desapropriada a Fazenda São José, no município de Nova Andradina, por isso acamparam às margens da rodovia BR-376, em frente ao trevo da entrada do extinto Frigorífico Independência, atualmente JBS S/A. $O$ acampamento, porém, precisou mudar de local, pois estava "atrapalhando os grandes compradores de carne da empresa", segundo o relato do assentado SO1 (entrevista realizada dia 24/1/2018).

Em seguida, os acampados foram avisados pelo Sindicato dos Trabalhadores Rurais de Nova Andradina de que a Fazenda Santa Olga estava em processo de desapropriação. Por isso, migraram com o acampamento até a frente da propriedade (sentido Nova Andradina-Ivinhema na rodovia BR-376, em torno de $8 \mathrm{~km}$ do acampamento da Fazenda São José). Os próprios assentados tinham dúvida sobre tal desapropriação, pois a propriedade estava toda estruturada, com cercamento, pastagens para o gado, curral e contava ainda com uma sede recém-construída pelo proprietário, avaliada em mais de um milhão de reais (especulações dos assentados). A garantia para continuar acampados chegava tanto dos funcionários do Incra quanto do Sindicato dos Trabalhadores Rurais. Depois de dois anos acampados, funcionários do Incra os autorizaram a mudar para dentro da propriedade e aguardar a divisão dos lotes. 
Outro ponto que domina as relações produtivas dos assentados refere-se à comercialização de sua produção. A organização de cooperativas nos assentamentos do município de Nova Andradina é pouco eficiente, e somente a Cooperativa de Produção dos Agricultores Familiares do Assentamento Santa Olga - Coopaolga - está funcionando, auxiliando na comercialização da produção dos assentados.

A não existência de organizações cooperativas permite a entrada de fornecedores externos e, principalmente, agroindústrias, como as beneficiadoras de leite, que, além de adquirir o leite dos assentados, fornece resfriadores para o armazenamento da produção, de forma individual (próprio) ou coletiva aos assentados (fixo em uma propriedade de acesso aos assentados). Essa dominação na aquisição e armazenamento do leite, bem como os insumos utilizados como forma de troca com a venda de leite, está mais presente nos Assentamentos Teijin e Casa Verde (que possuem vários fornecedores de compra de leite), porém os Assentamentos Santa Olga e São João passam por condições similares.

\section{TERRITORIALIDADE NOS ASSENTAMENTOS RURAIS DE NOVA ANDRADINA/MS}

Cada assentamento possui características próprias e movimentos socioterritoriais, ${ }^{4}$ formados de acordo com sua configuração local, seja pela trajetória das famílias, pela organização interna dos assentados, pelas relações de poder permeadas nessa fração do território capitalista ou pelas relações produtivas peculiares de cada assentamento em um mesmo município. A abordagem territorial nos assentamentos rurais permite compreender que a passagem de um sistema latifundiário para frações de lotes possibilita a criação de novos processos territoriais em uma mesma localidade.

A nova configuração territorial a partir dos assentamentos rurais conduz à problematização deste campo de pesquisa com as relações sociais particulares em qualquer aspecto, pois cada fração do território construído tem suas distinções em tamanho dos lotes, fertilidade do solo, lutas das famílias assentadas, processos de produção, relações de poder, infraestrutura de suas instalações, enfim, cada particularidade permite descobrir uma diversidade de movimentos socioterritoriais no interior de cada assentamento rural em um mesmo município.

Neste caso, o município de Nova Andradina possui quatro Projetos de Assentamentos, com dimensões territoriais e de famílias assentadas distintamente um do outro, contextualizados no que se refere às políticas de assentamentos rurais no país. Esta produção de territórios nos assentamentos do município, criando e recriando práticas camponesas, promove novas frentes de desenvolvimento local, sobretudo nas relações que transitam dentro dos lotes. Sua dinâmica de trabalho e suas relações comerciais in-

\footnotetext{
${ }^{4}$ Para Fernandes (2012, p. 31), "os movimentos socioterritoriais têm o território não só como trunfo, mas este é essencial para sua existência. Os movimentos camponeses, os indígenas, as empresas, os sindicatos e os Estados podem se constituir em movimentos socioterritoriais e socioespaciais. porque criam relações sociais para tratarem diretamente de seus interesses e assim produzem seus próprios espaços e seus territórios. No campo e na floresta, os movimentos socioterritoriais são predominantemente movimentos camponeses, movimentos camponesesindígenas e movimentos indígenas em luta pela terra e pelo território".
} 
serem a novos territórios não existentes antes da desapropriação, e, com a criação dos PAs, novas fronteiras são construídas, seja no âmbito social, econômico e cultural da região em que estão instalados.

Raffestin (1993, p. 2) descreve que "ao se apropriar de um espaço concreto ou abstratamente, o ator territorializa o espaço", seja em qualquer momento ou lugar, pois somos atores que produzimos "territórios". Aludido destas definições ao cenário dos assentamentos rurais, percebe-se como tal realidade permite transformar e movimentar as relações sociais, econômicas, políticas e culturais de determinada comunidade. Para o autor, esta territorialidade se manifesta em todas as dimensões espaciais e sociais, relações estas que são compreendidas em um sistema tridimensional sociedade-espaço-tempo, inserindo-se no quadro da produção, da troca e do consumo daquela localidade/região destes assentamentos rurais. Em suma, pode-se afirmar que:

O território não é o espaço, mas uma produção derivada da sua apropriação. Nessa perspectiva o território é um espaço transformado pelo trabalho ali contido, o qual é delineado por estratégias de organização e controle do mesmo. Portanto, essa apropriação não é uma ocorrência natural, mas um dado concreto da luta dos homens pela sua sobrevivência (RAFFESTIN, 1993, p. 144).

Cada assentamento rural possui uma história com seus assentados, realizando sua trajetória fundamentada em suas relações sociais, culturais, econômicas e de poder e/ ou enraizadas com o tempo de luta e vivência no campo.

Segundo Fernandes (2008, p. 42), os "territórios em movimento produzem múltiplas territorialidades e territorializações, desterritorializando e reterritorializando relações sociais", que geram conflitos e manifestações por meio da contradição, criando e recriando problemas. Refletindo este pensamento sobre o território nos assentamentos, partimos do princípio de que as relações existenciais antes, durante e depois da criação de projetos de assentamentos rurais, são dinâmicas mutáveis, que se renovam de acordo com suas relações sociais nesta fração de território capitalista.

O território, para Fabrini e Roos (2014), é a maneira de apreender a complexidade da realidade agrária nos assentamentos rurais. Relatam ainda que nos projetos de assentamentos de reforma agrária está presente a forte expressão territorial camponesa, pois ocorre a desterritorialização dos proprietários latifundiários de posse das terras para o domínio territorial dos sem-terra daquela mesma propriedade e/ou localidade.

Para Haesbaert (2004), nenhuma sociedade pode viver sem território. Com isso, podemos refletir sobre como a migração do assentado está relacionada ao seu poder de se territorializar em outro espaço rural, sobretudo os assentamentos rurais, seja ele em qualquer localidade, mesmo distante de suas raízes no campo.

O território será por nós analisado a partir das relações sociais de produção, levando em consideração o cenário dos assentamentos rurais que parte das lutas de classe, que buscam, por meio da posse da terra, a sua reprodução social e sua existência, gerando novas configurações sociais nesta fração de território, desconstruindo a lógica de um território fixo e recriando novas territorialidades. Para Oliveira:

O território é assim, produto concreto da luta de classes travada pela sociedade no processo de produção de sua existência. Sociedade capitalista que está assentada em três classes fundamentais: proletariado, burguesia e proprietários de terra. 
Dessa forma, são as relações sociais de produção e o processo contínuo/contraditório de desenvolvimento das forças produtivas que dão a configuração histórica específica ao território (2007, p. 3).

Fabrini e Roos (2014, p. 66) acrescentam que o território é formado a partir das contradições sociais e dos processos de produção, fazendo dos assentamentos rurais uma potencialidade de resistência e força territorial, pois "assentar na terra é dominar, controlar e ter poder sobre o espaço, o que conforma o território". Para os autores, a partir da terra e/ou lote conquistado novas relações serão desdobradas nesta territorialização, alimentando a força dessa fração do território, recriando um conjunto de novos saberes e conhecimentos do campesinato local.

Para Paulino (2006), a produção do território dos camponeses se dá por meio de lutas, que se inscrevem em um campo de poder e que interagem com o território capitalista, a sociedade, o espaço e o tempo, pautados na classe camponesa nesta fração de território. Este processo de territorialização não se limita apenas nas propriedades individuais; são relações sociais de reprodução da classe camponesa, que transcendem o sentido econômico da atividade e possibilitam novos parâmetros de ordenação territorial no campo.

Raffestin (1993) nos permite admitir que o território se forma a partir do espaço, sendo o resultado de uma ação conduzida por atores sociais relacionados em qualquer âmbito. Ao se apropriar de um espaço, o ator territorializa o espaço no qual está vivendo. O espaço, portanto, que se tornou o território de um ator social, com suas configurações históricas, seus conflitos relacionais de classe, suas origens e posições sociais, faz dos assentamentos rurais um campo imenso de complexidades e de trajetórias de luta pela terra; uma fração de território rico em conflitualidades, tradições e objetivos distintos dos camponeses nos Estados brasileiros.

Em uma discussão mais conceitual, amparada no entendimento de Fernandes (2005), descrevemos a correlação entre conflitos e conflitualidades, presentes na pesquisa e nos Projetos de Assentamentos do município de Nova Andradina/MS:

Um conflito por terra é um confronto entre classes sociais, entre modelos de desenvolvimento, por territórios. O conflito pode ser enfrentado a partir da conjugação de forças que disputam ideologias para convencerem ou derrotarem as forças opostas. Um conflito pode ser "esmagado" ou pode ser resolvido, entretanto a conflitualidade não. Nenhuma força ou poder pode esmagá-la, chaciná-la, massacrá-la. Ela permanece fixada na estrutura da sociedade, em diferentes espaços, aguardando o tempo de volta, das condições políticas de manifestações dos direitos. [...] Os acordos, pactos e tréguas definidos em negociações podem resolver ou adiar conflitos, mas não acabam com a conflitualidade, porque esta é produzida e alimentada dia-a-dia pelo desenvolvimento desigual do capitalismo (p. 26).

Raffestin (1993) revela que o poder é consubstancial em todas as relações. A manifestação vivencia-se em um campo de poder, alicerçado em suas relações de força locais, regionais, nacionais e mundiais. Para o autor, todas as relações possuem um lugar de poder, e estes estão ligados intrinsecamente no comando dos fluxos que transitam nas relações, sob a energia e a informação envolvidas nestes ambientes. No espaço po- 
lítico dos ambientes, o território é o melhor campo de ação do poder e seus trunfos, visando o controle e a dominação das pessoas e dos processos estruturais deste território.

Ao nos referirmos ao conceito de poder manifestado nos assentamentos rurais, nos dirigimos às problematizações sustentadas por Foucault (1988), que relata que o poder não se apresenta em um lugar determinado do contexto social. Ao contrário, ele funciona como uma rede de dispositivos que caracteriza uma relação também marcada por mecanismos de resistência, mas dispersa nas relações, sempre suscetível de gerar um chamado contrapoder, a resistência. De acordo com o autor, não existe algo uno ou global que possa ser chamado de poder, mas formas heterogêneas e em constante transformação. Dessa maneira, é possível afirmar que ele - o poder - marca/versa os corpos na medida em que os condiciona a determinadas condutas e ao fazer de sua construção social, uma ordem natural que introduz características peculiares e essenciais aos sujeitos sociais.

As relações existentes do poder estão conjugadas em meio a fatores dentro e fora dos assentamentos. Atentamo-nos a essas faces antes mesmo de se estabelecer uma fração de território denominado assentamento, ao que diz respeito às faces vividas do proprietário de terra, o "dono" da fazenda, o patrão, o latifundiário que possui a posse da terra, sob a discussão de improdutividade e conflitos sociopolíticos. Nessa propriedade, que é motivo de lutas e, em alguns casos, de vidas ceifadas, depois de muito tempo um novo território é construído, sob a espera da posse de seus lotes.

Com a pretensão de compreender as relações de poder a partir da fração dos territórios dos assentamentos rurais, Fernandes (2008, p. 42) nos apresenta uma reflexão a partir da vivência dos assentados, pois os "territórios colidem, são destruídos e recriados por meio de relações de poder", produzindo novas bases sociais naquela localidade. Essas novas bases sociais produzidas por estas recriações territoriais determinam novas relações sociais naquele território, porém agora com novos atores e um cenário distinto do anterior, quando novas raízes serão construídas e novos poderes serão colididos nesta localidade rural.

Diante da importância dos Projetos de Assentamentos Rurais no campo social e econômico, Schneider (2010) revela que os mecanismos de dominação social são construídos historicamente no campo brasileiro, pois as elites de cada localidade, no uso de seu poder socioeconômico esbarram e alteram as condições de vida das populações, provocando rupturas na distribuição de terras para reforma agrária.

As relações marcadas pelo poder nos territórios são sustentadas pela prática espacial dos indivíduos, por meio de seus comportamentos e ações, representadas nas tessituras, nós e redes organizadas de maneira hierárquica, assegurando o controle daquele território. Raffestin (1993, p. 151) revela que a posse dos modos de produção e das relações sociais de comunicação, "permitem realizar a integração e a coesão dos territórios", ordenando o território de acordo com a organicidade dos indivíduos e seus grupos, constituído sob os sistemas territoriais, formando as relações de poder.

O poder se manifesta de acordo com as relações existenciais em determinado espaço, sendo cada relação um lugar de poder, presente em cada ação desencadeada de um evento, segundo Raffestin (1993). Estas relações existenciais, reunidas às relações 
produtivas a partir da construção dos indivíduos em seu sistema tridimensional, presentes na sociedade-espaço-tempo, adquirem um valor particular, traduzindo-se em uma produção territorial, que, por meio de um sistema de ações e comportamentos, estabelece uma territorialidade vivida pelos membros de uma coletividade.

O camponês possui predicados mais enraizados com a terra e seu núcleo familiar não somente para o autoconsumo, mas uma concepção que transcende a característica econômica, propostos nas "[...] características da sua organização social, como o trabalho familiar, os costumes de herança e a tradição religiosa" e, entre outras formas comportamentais que possibilitam não somente o contraditório de viver em meio ao "campo dos negócios", mas reproduzir socialmente a sua organização de produção camponesa (MOURA, 1986, p. 69).

Para Almeida (2003, p. 28), a recriação camponesa na parcela de domínio do território nos assentamentos rurais, mediante a conflitualidade dos camponeses com a produção capitalista do território, produz um processo de territorialização camponesa naquela localidade, que, segundo a autora, é fundamentada numa "teia de relações que tem na família, na reciprocidade, na economia moral, na autonomia seu elo identificatório". Por meio do reconhecimento desses atores sociais, possuidores e portadores de uma mesma linguagem, seus processos de reprodução social são contestados pela produção capitalista, que se opõem a este modo de vida no campo.

Os assentamentos rurais representam uma fração do território no campo; eles possuem qualidades e devem ser compreendidos em seus espaços territorializados, que transformam o espaço geográfico, modificando as paisagens e construindo novos territórios, regiões e lugares, que, para Fernandes (2012), pode ser produzido da seguinte maneira:

O território é o espaço apropriado por uma determinada relação social que o produz e o mantém a partir de uma forma de poder. [...] o território possui limites, possui fronteiras, é um espaço de conflitualidades, formada a partir de diferentes relações sociais. O território é, ao mesmo tempo, uma convenção e uma confrontação. Sua configuração como território refere-se às dimensões de poder e controle social que lhes são inerentes. Desde essa compreensão, o território mesmo sendo uma fração do espaço também é multidimensional. Essas qualidades dos espaços evidenciam nas partes as mesmas características da totalidade. A intencionalidade é uma visão de mundo, ampla, todavia una, é sempre uma forma, um modo de ser, de existir. Constitui uma identidade (p. 27).

O espaço multidimensional pode ser entendido como uma combinação de múltiplas determinações que, segundo Mizusaki (2008), articulam-se contraditoriamente, gerando movimentos socioterritoriais e produzindo a territorialização dos processos no campo. Determinações são produzidas historicamente, seja de ordem geográfica, econômica, social, política, cultural, entre outros fatores, que se articulam diferencialmente. Nesse sentido, os fatores econômicos não são os únicos responsáveis pela diferenciação social no campo brasileiro.

Almeida (2003) traz uma reflexão do dilema do campesinato brasileiro que, segundo a autora, está relacionado à formação histórica que produz a contradição entre a permanência, a mudança e a transformação, e não simplesmente o conservadorismo sobre o moderno, mas compreender que a luta diária de sua reprodução social está 
pautada na base de seus valores ditos tradicionais, como família, terra e trabalho. A condição de assentado transcende a simples materialidade da propriedade, com questões relacionadas à vivência histórica da vida no campo liberto.

\section{CONSIDERAÇÕES FINAIS}

As relações de poder estão presentes em todos os ambientes em que os assentados estão inseridos. Estas relações ocorrem na resistência em lutar pela desapropriação de terra, pelas batalhas judiciais, pelos enfrentamentos com arrendatários, pela espera do cumprimento das políticas públicas, pela expulsão do local de acampamento adentrando em lotes sem a devida condição de trabalho, enfim, em resistir lutando contra o poder do Estado e dos grandes proprietários de terra em busca da efetiva política de reforma agrária.

Estas territorialidades existenciais nos assentamentos do município de Nova Andradina, como a comercialização e produção de suas mercadorias, seu convívio social e político nas comunidades locais, seguem além das relações de poder do Estado, isto é, acontecem nas próprias relações entre os assentados e suas lideranças. Por meio de suas associações, cooperativas e áreas de produção coletiva, os assentados possuem resistências na coparticipação como membros dessas organizações, seja por questões culturais de cada assentado ou por suas relações com as diretorias no modo de operação das organizações.

A trajetória dos assentados traz diversas experiências de confrontos e de organização na criação dos assentamentos, os seus movimentos socioterritoriais (Movimentos dos Trabalhadores Rurais Sem Terra - MST) e organizações sindicais (Fetagri/MS), constituídos a partir de possíveis coesões nos espaços de poder que possibilitam desdobramentos de direitos e conquistas, representados pela mobilização de atores do poder local, possibilitando a realização dos assentamentos.

Esta força rompe uma territorialidade já concebida, sendo reconstruído um novo território nesta fração de território capitalista (os assentamentos rurais), resultado das relações de poder manifestadas pelos camponeses ou de qualquer outro movimento. Os assentamentos rurais são territórios em permanente disputa, que seguem além dos conflitos com o latifundiário e o Estado, mas também entre os próprios camponeses, gerando resistências em vários níveis.

\section{REFERÊNCIAS}

ALBERTI, Verena. Manual de história oral. 1. ed. rev. e atual. Rio de Janeiro: Editora FGV, 2004.

ALMEIDA, Rosemeire Aparecida de. Identidade, distinção e territorialização: o processo de (Re) criação camponesa no Mato Grosso do Sul. 2003, 391f. Tese (Doutorado em Geografia) - Unesp, Presidente Prudente, 2003.

BERTAUX, Daniel. Los relatos de vida: perspectiva etnosociológica. Barcelona: Bellaterra, 2005 FABRINI, João Edmilson; ROOS, Djoni. Conflitos territoriais entre o campesinato e o agronegócio latifundiário. 1. ed. São Paulo: Outras Expressões, 2014.

FERNANDES, Bernardo Mançano. Desenvolvimento territorial: conflitualidade e sustentabilidade. Inédito, 2005.

FERNANDES, Bernardo Mançano. Questão agrária: conflitualidade e desenvolvimento territorial. In: BUAINAIN, Antônio Márcio (ed.). Luta pela terra, reforma agrária e gestão de conflitos no Brasil. Campinas: Editora da Unicamp, 2008. p. 173-224. 
FERNANDES, Bernardo Mançano. Movimentos socioterritoriais e movimentos socioespaciais: contribuição teórica para uma leitura geográfica dos movimentos sociais. Revista Nera, n. 6, p. 24-34, 2012.

FERNANDES, Bernardo Mançano. Movimento social como categoria geográfica. Terra Livre, n. 15, p. 5986, 2015.

FOUCAULT, Michel. Microfísica do poder. Rio de Janeiro: Graal, 1988.

HAESBAERT, Rogério. O mito da desterritorialização. Rio de Janeiro: Bertrand Brasil, 2004. V. 2.

IBGE. Instituto Brasileiro de Geografia e Estatística. Estimativas da população residente no município de Nova Andradina ? Mato Grosso do Sul. Brasília, DF, 2018. Disponível em: https://cidades.ibge.gov.br/brasil/ms/nova-andradina/panorama. Acesso em: 25 jul. 2018.

IBGE. Instituto Brasileiro de Geografia e Estatística. Estabelecimento e área da agricultura familiar, segundo as Unidades da Federação, Mesorregiões, Microrregiões e Municípios. Censo Agropecuário 2006. Brasília, DF, 2006. Disponível em: ftp://ftp.ibge.gov.br/Censos/Censo_Agropecuario_2006/agri_familiar_2006/. Acesso em: 3 fev. 2015.

INCRA. Instituto Nacional de Colonização e Reforma Agrária. Painel dos assentamentos. Superintendência Regional Mato Grosso do Sul ? SR 16. Todos os assentamentos, 2018. Disponível em: http://painel.incra. gov.br/sistemas/index.php. Acesso em: 2 ago. 2018.

MEIHY, José Carlos Sebe Bom; RIBEIRO, Suzana L. Salgado. Guia prático de história oral: para empresas, universidades, comunidades, famílias. São Paulo: Contexto, 2011.

MINAYO, M. C. de S. Pesquisa social: teoria, método e criatividade. 21. ed. Petrópolis: Editora Vozes, 2002. MIZUSAKI, Márcia Yukari. Diferenciação e mobilidade socioterritorial do campesinato: o caso da avicultura de corte em Mato Grosso do Sul. In: ALMEIDA,. Rosemeire Aparecida de (org.). A questão agrária em Mato Gross do Sul: uma visão multidisciplinar. Campo Grande, MS: Editora UFMS, 2008.

MOURA, Margarida Maria. Camponeses. São Paulo: Editora Ática, 1986.

OLIVEIRA, Ariovaldo Umbelino. Modo de produção capitalista, agricultura e reforma agrária. São Paulo: FFLCH, 2007. 184p.

PAULINO, Eliane Tomiasi. Por uma geografia dos camponeses. São Paulo: Editora Unesp, 2006.

PMNA. Prefeitura Municipal de Nova Andradina. Histórico. Disponível em: http://www.pmna.ms.gov.br/ historia. Acesso em: 16 maio 2017.

POUPART, Jean et al. A pesquisa qualitativa: enfoques epistemológicos e metodológicos. In: A pesquisa qualitativa: enfoques epistemológicos e metodológicos. Petrópolis: Vozes, 2014.

RAFFESTIN, Claude. Por uma geografia do poder. São Paulo: Ática, 1993.

SCHNEIDER, Sérgio. Situando o desenvolvimento rural no Brasil: o contexto e as questões em debate. Revista de Economia Política, v. 30, n. 3, p. 511-531, 2010.

TRIVIÑOS, Augusto Nibaldo Silva. Introdução à pesquisa em ciências sociais: a pesquisa qualitativa em educação. São Paulo: Atlas, 1987. 